\title{
The threats posed by the pet trade in alien terrestrial invertebrates in South Africa
}

\author{
Takalani Nelufule ${ }^{\mathrm{a}, \mathrm{b}, *}$, Mark P. Robertson ${ }^{\mathrm{a}}$, John R.U. Wilson ${ }^{\mathrm{b}, \mathrm{c}}$, Katelyn T. Faulkner ${ }^{\mathrm{a}, \mathrm{b}}$, \\ Catherine Sole $^{\mathrm{d}}$, Sabrina Kumschick ${ }^{\mathrm{b}, \mathrm{c}}$ \\ ${ }^{\text {a }}$ Centre for Invasion Biology, Department of Zoology and Entomology, University of Pretoria, Pretoria, South Africa \\ ${ }^{\mathrm{b}}$ South African National Biodiversity Institute, Kirstenbosch Research Centre, Cape Town, South Africa \\ ${ }^{\mathrm{c}}$ Centre for Invasion Biology, Department of Botany and Zoology, Stellenbosch University, Stellenbosch, South Africa \\ ${ }^{\mathrm{d}}$ University of Pretoria, Pretoria, South Africa
}

\section{A R T I C L E I N F O}

\section{Keywords:}

Biological invasions

DNA barcoding

e-commerce

EICAT

Impact assessment

SEICAT

\begin{abstract}
A B S T R A C T
The pet trade has been a major pathway for the introduction of vertebrate invaders, but little is known about its role in invertebrate invasions. Here we assess the trade in terrestrial invertebrates (excluding spiders) in South Africa and the potential of this trade to result in biological invasions and impacts. Pet stores, websites, and expositions were visited, and a list of the taxa traded was compiled. DNA barcoding was used to determine if the species were correctly identified in the trade. Information on invasion history and impact elsewhere was used to assess the potential for species to become invasive and have impact in South Africa. We found 53 alien terrestrial invertebrate taxa that were traded, although only 36 of these matched a valid species name. Of 11 species tested using DNA barcoding nine were correctly identified. Species accumulation curves were produced, but did not reach an asymptote, suggesting there are many species in the trade that were not recorded. The most common species were used as food for pets, rather than as pets themselves. None of the species were reported to be invasive elsewhere, and few had records of causing negative impacts (the exception being moderate impacts to human health caused by venomous scorpions). Therefore, there is little evidence that the invertebrates traded pose a significant threat to South Africa. However, given uncertainties in which taxa are traded and the lack of data on invasiveness and impact, there might be a significant invasion debt. We recommend continued monitoring and engagement with the industry.
\end{abstract}

\section{Introduction}

Every year, billions of live animals are transported around the world as part of the pet trade (Broad, Mulliken, \& Roe, 2003; Karesh, Cook, Bennett, \& Newcomb, 2005; Kopecky, Patoka, \& Kalous, 2016). Species are traded for ornamental ( $\mathrm{Ng}$ et al., 2016) and recreational purposes (Cambray, 2003), and as food for pets (Haggett, 2013). Once these species are in the pet trade, they could be released by humans or escape from captivity (Cadi \& Joly, 2003; Faulkes, 2010). Those individuals or populations of introduced species that are able to survive and reproduce can become invasive (Ernst \& Lovich, 2009). For example, in South Africa, the common myna (Acridotheres tristis) was introduced into the pet trade, later escaped, and has subsequently spread throughout southern Africa (Peacock, van Rensburg, \& Robertson, 2007). The increased popularity of alien pets has led to more species being introduced globally, making the pet trade a significant pathway for introducing new species (van Wilgen et al., 2010; Papavlasopoulou, Vardakas, Perdikaris, Kommatas, \& Paschos, 2013; Mori et al., 2017; Lockwood et al., 2019).

There are many different sources (e.g. pet stores and internet) from which people can obtain pets. As with the trade in other commodities, there has been an increasing amount of trade in pets over the internet (Kikillus, Hare, \& Hartley, 2012; Derraik \& Phillips, 2010). For example, over 500 terrestrial invertebrate species are offered for sale on one website alone (https://www.bugzuk.com; accessed: 4 June 2017). The internet has thus increased accessibility to more species from a

Abbreviations: AIC, Akaike Information Criterion; COI, Cytochrome c oxidase subunit I; BIC, Bayesian Information Criterion; BLAST, Basic Local Alignment Search

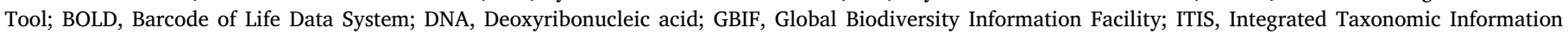
System; MC, Minimal Concern; MN, Minor; MO, Moderate; MR, Major; MV, Massive; DD, Data Deficient; MP, Maximum Parsimony; NJ, Neighbour-joining

* Corresponding author.

E-mail address: takalani.nelu@gmail.com (T. Nelufule). 
range of taxa (Bush, Baker, \& Macdonald, 2014).

The likelihood that species sold in the pet trade will establish is affected, in part, by the number of different species introduced (i.e., the colonisation pressure) and the number of individuals of a specific species introduced in combination with the number of introduction events (i.e., the propagule pressure) (Lockwood, Cassey, \& Blackburn, 2009). The more species introduced into a single area, the higher the likelihood that one of these species will be able to establish and become invasive. Similarly, the higher the propagule pressure of a specific species, the more likely that species will establish and become invasive. The size of the trade, in terms of the number of species and the number of individuals of those species traded, therefore determines colonisation and propagule pressure (Marr et al., 2017). Moreover, humans also directly influence the probability of an invasion by either keeping specimens in captivity (and so, to various degrees, limiting the likelihood of an unintentional escape) or by intentionally releasing individuals (Maceda-Veiga et al., 2019).

In South Africa, the role of the pet trade as a pathway for the introduction of species has been studied for reptiles (van Wilgen et al. 2010), amphibians (Measey et al., 2017), and tarantulas (Shivambu, 2018). But there has not been a general assessment of the terrestrial invertebrate trade. However, at least one traded terrestrial invertebrate species has escaped from captivity and established. The Indian walking stick insect (Carausius morosus) was introduced to South Africa for research purposes and as a pet species, and subsequently established a population in the Cape Floristic Region (Picker \& Griffiths, 2011; Picker, Griffiths, \& Weaving, 2002). After the species established, the whole order Phasmatodea was regulated in South Africa under the Alien and Invasive Species Regulations of the National Environmental Management: Biodiversity Act [NEM:BA A\&IS Regulations (DEA, 2016)] - however there has not been a detailed risk analysis conducted for any of the species in this group to date.

If an invasion does occur, it can cause devastating environmental and socio-economic impacts (Olson, 2006; Vila et al., 2011). Invasive species can outcompete native species (Cadi \& Joly, 2004; Polo-Cavia, Lopez, \& Martın, 2008), cause biodiversity loss (Wan, Guo, \& Wang, 2002), and spread diseases and pathogens that are harmful to humans or native species (Haenen, Way, Bergmann, \& Ariel, 2004; Weir et al., 2012). For example, the red imported fire ant (Solenopsis invicta), which is native to south America, is invasive in Texas and has reduced the diversity of native ants in areas where it has invaded (Porter \& Savignano, 1990). In order to address these impacts, Aichi Biodiversity Target 9 specifies that damaging alien species should be identified and prioritised for management (CBD, 2013).

Countries, therefore, need to compile an inventory of alien species as it serves as a first reference point in the management of biological invasions (Roy et al., 2014). These inventories are needed in order to know which species are present and potentially harmful, and which species require management (Latombe et al., 2016; McGeoch, Spear, Kleynhans, \& Marais, 2012; Regan, Colyvan, \& Burgman, 2002). Accurate and taxonomically correct lists are also important because they can help inform the prevention of future invasions. However, even lists of supposedly well-known groups contain many errors and inconsistencies (e.g., Magona, Richardson, Le Roux, Kritzinger-Klopper, \& Wilson, 2018). This is particularly an issue in the pet trade where valid scientific names are not consistently used (Bartlett, Griswold, \& Bartlett, 2001) and species are misidentified (Petersen et al., 2007).

Once an inventory of alien species is compiled, one of the most common approaches to identify the taxa that could cause harm is to estimate the likelihood and consequence of an invasion by a particular species by assessing its history of invasion and impact elsewhere in its introduced range (Hulme, 2012; Kulhanek, Ricciardi, \& Leung, 2011; Weber, Panetta, Virtue, \& Phelong, 2009). To facilitate such analyses, various impact scoring schemes have been developed in order to assess the impact of alien species and facilitate their prioritisation for management, for example the Environmental Impact Classification for Alien
Taxa (EICAT) and Socio-Economic Impact Classification for Alien Taxa (SEICAT) (Bacher et al., 2018; Hawkins et al., 2015).

The aims of this study were to: 1 ) determine the size of the trade (number of species and their availability) in alien terrestrial invertebrates in South Africa; 2) test the accuracy of the identification of the traded terrestrial invertebrates using DNA barcoding; 3) assess the uses of the traded species; and 4) assess the potential of the traded species to become invasive and cause negative impacts.

\section{Materials and methods}

\subsection{Data collection}

We considered three main ways in which alien terrestrial invertebrates are sold as part of the pet trade - in pet stores; at expositions (large public exhibitions where breeders, pet stores owners and hobbyists gather to sell and buy a variety of species); and over the internet (both dedicated commercial sites and sales offered on general sites). A total of 64 pet stores, 12 websites, and 18 breeders (from five different expositions) were visited. As there are a large number of tarantula species in the South African pet trade (ca. 200 species), the trade in tarantulas was assessed in a separate dedicated study (Shivambu, 2018).

\subsection{Pet stores}

Initially, pet store locations were gathered by searching the internet using the Google search engine and key words such as "pet stores around Pretoria" (search string) and "pet stores in Johannesburg". The pet stores identified in Pretoria, Johannesburg, Cape Town, and Durban (i.e. the major urban centres of South Africa), as well as those found in the vicinity of these stores, were visited during 2016 and 2017. When visiting the pet stores identified through our online search, we asked the managers of these stores for the names of pet stores in the vicinity in order to identify additional pet stores. We were unable to sample all pet stores across South Africa but aimed to obtain a sample of pet stores in four major cities. We spent at least four days in each city and surveyed 27 pet stores in Pretoria, eight in Johannesburg, 13 in Cape Town, and 16 in Durban. We also visited pet stores in the Gauteng Province to purchase specimens for DNA barcoding (see below for further details). DNA specimens were collected from the Gauteng Province because most of the species chosen for DNA barcoding were recorded there and expositions are held in this province where most pet store owners and breeders from different parts of the country gather and sell their taxa. In each pet store, we recorded the names of the species traded and their uses. Species names were recorded as provided by the pet stores.

\subsection{Expositions}

We visited breeders at pet expositions in Kempton Park and Johannesburg in the Gauteng Province. Expositions' locations were gathered by searching the internet using Google and by consulting flyers distributed at the visited pet stores. We investigated five expositions over two consecutive years (2016 and 2017). We spent two days at each exposition and recorded the names of the terrestrial invertebrate species that were available as provided by the breeders, and their uses.

\subsection{Websites}

Google was used to search for South African online pet stores (hereafter referred to as "websites"). Search terms such as "exotic pets", "insects" and "invertebrate pets for sale" were used to search for websites. Online advertising websites such as Facebook (https://www. facebook.com), Gumtree (https://www.gumtree.co.za), Ananzi (https://www.ananzi.co.za), Junk mail (https://www.junkmail.co.za), 
and OLX (https://www.olx.co.za), were searched for terrestrial invertebrates offered for sale using the following search terms: "exotic pets, insects and invertebrate pets for sale", "feeders insects", "cockroaches", "scorpions", "stick insects", "snails" and "terrestrial invertebrates for sale". Eight other online pet stores were searched, but to protect their identify, are not mentioned here by name. We only searched websites with a South African domain name, except for Facebook, (i.e. addresses ending in ".co.za"). In order to account for possible species turnover, searches were performed on the last day of the month, every two months between June 2016 and November 2017. We recorded the names of the species traded and their uses. The names of the species sold on the websites were recorded as provided.

\subsection{Size of the trade in terrestrial invertebrates}

Most species names that were recorded were common names. Species names (common and scientific names) were verified using the Integrated Taxonomic Information System (ITIS, 2017) and the Global Biodiversity Information Facility (GBIF, 2017). In this manuscript, verified species names are referred to as 'confirmed' species while those that were not verified are referred to as 'unconfirmed' species. In order to get an indication of the size of the trade in terrestrial invertebrates, we analysed the collected data using species accumulation curves. These accumulation curves were generated using the 'vegan' package in R (Oksanen et al., 2017).

An availability index was calculated by counting the number of times that a pet store, website, or exposition stocked a species [see Vallllosera and Cassey (2017), for an example of this approach].

\subsection{Identity of the traded species}

To check the identity of the species we used a DNA barcoding approach based on sequences of cytochrome oxidase I gene [which has been successfully used to identify terrestrial invertebrate species such as tarantulas (Petersen et al., 2007)]. We selected species that were most available during the surveys (species with availability index of nine and above, see Table A.1) and those regulated under the South African National Environmental Management: Biodiversity Act, Alien and Invasive Species Regulations (NEMBA: A\&IS Regulations) (DEA, 2014). To get a range of samples, specimens of each species were purchased from three different pet stores where possible. Working with terrestrial invertebrates does not require an ethics application at the University of Pretoria and therefore no ethics application was acquired. The final dataset consisted of 27 specimens sold under 11 distinct species names (see Appendix A for the full DNA barcoding methods).

\subsection{Uses of traded species}

Information on the use of each species was obtained during searches for species sold by online pet stores and during visits to pet stores and expositions. The majority of the websites provided uses for each species offered for sale. At the expositions, breeders, hobbyists, and pet store owners were asked to specify the use of each terrestrial invertebrate species they were trading and/or purchasing. The ethics approval for interviewing people was obtained from the University of Pretoria ethics committee.

\subsection{Invasion potential and impact assessment}

To collate information on invasion histories and impact, the ISI Web of Knowledge, Google Scholar as well as biological invasion websites and databases such as the Global Invasive Species Database (www. iucngisd.org/gisd) were used to search for scientific publications and grey literature on the traded species. Common names and scientific names were used as search strings, as well as other relevant search terms (e.g. mealworms). Publications were manually filtered based on the information provided in the title and abstracts. The references cited within the identified publications were also screened.

Any records that the species found in the pet trade had a history of invasion elsewhere were noted. The identified references were also searched for information on impacts of the species and the information provided was extracted and used to assess the magnitude of impact using the Environmental Impact Classification for Alien Taxa and SocioEconomic Impact Classification for Alien Taxa (EICAT and SEICAT, respectively) (Bacher et al., 2018; Hawkins et al., 2015). EICAT was developed by Blackburn et al. (2014) to assess the magnitude of environmental impacts, and has recently been adopted by the IUCN to ensure the standardised assessment of the impacts of alien species globally (IUCN, 2020). SEICAT assesses changes to human well-being and livelihoods by considering the impact of alien species on human activities based on different constituents of well-being (Bacher et al., 2018). These schemes can also aid in the identification of species with large potential impacts in areas where they have not yet been introduced and so inform preventative management.

For each assessed species, a confidence score of high, medium or low was designated according to the quality of the data acquired during the assessment (Hawkins et al., 2015). For analysis, the maximum impact scores per species for EICAT and SEICAT were used (Blackburn et al., 2014; Hawkins et al., 2015; Bacher et al., 2018).

\section{Results}

We recorded 60 names of terrestrial invertebrate taxa in the pet trade, of which seven correspond to species native to South Africa (Scorpiones; Parabuthus capensis, Parabuthus transvaalicus, Hadogenes troglodytes, Blattodea; Oxyhaloa deusta, Coleoptera; Anisorrhina flavomaculata, Rhabdotis aulica and Pachnodasinuata). These native species were excluded from further analysis. Of the other 53 taxa, 36 names (i.e. $64 \%$ ) corresponded to species alien to South Africa while 17 names could not be linked to a valid species on ITIS and GBIF, and so their status as natives or aliens is uncertain. Eleven of the confirmed species were sold at pet stores, six at expositions and 19 online, while 11 of these species were available from all three sources and three from expositions and online. Of all the species recorded, only one species (the Australian stick insect, Extatosoma tiaratum) is listed under the NEM:BA A\&IS Regulations (DEA, 2016), although the listing is for the whole order Phasmatodea, rather than E. tiaratum specifically. Most of the alien invertebrate species sold in the pet trade $(62 \%)$ are insects (Fig. 1).

The species accumulation curves of the number of names of species sold by websites, breeders and pet stores did not reach an asymptote (Fig. 2).

For the 27 alien terrestrial invertebrate specimens assessed using DNA barcoding, 22 specimens were correctly identified and matched with the species names provided by the publicly accessible database BLAST, with identity matches of greater than $93 \%$ (Fig A.1). Five specimens belonging to two species, Achatina immaculata (two specimens) and Pandinus imperator (three specimens), were not correctly identified (Fig. A.1). Extatosoma tiaratum was correctly identified, with an identity match of greater than $99 \%$, although the precise species name would not matter for the regulations as it was obviously a stick insect (Fig A.1).

The terrestrial invertebrates could be placed in three broad classes of usage, namely pets [e.g. emperor scorpion (Pandinus imperator)], pet food [e.g. mealworms (Tenebrio molitor)], and cleaners [two insect species, the hide beetle (Dermestes maculatus) and the litter beetle (Alphitobius diaperinus), are used to clean animal cages] (Table A.1). Additionally, an unconfirmed species of earthworm is used for soil improvement. Of the traded species, those with the highest availability were species that were used for pet food (Fig. 3). All seven unconfirmed species of terrestrial invertebrates were sold as pet food. Twelve of the top 13 most available species were insects and all 12 were used as pet 


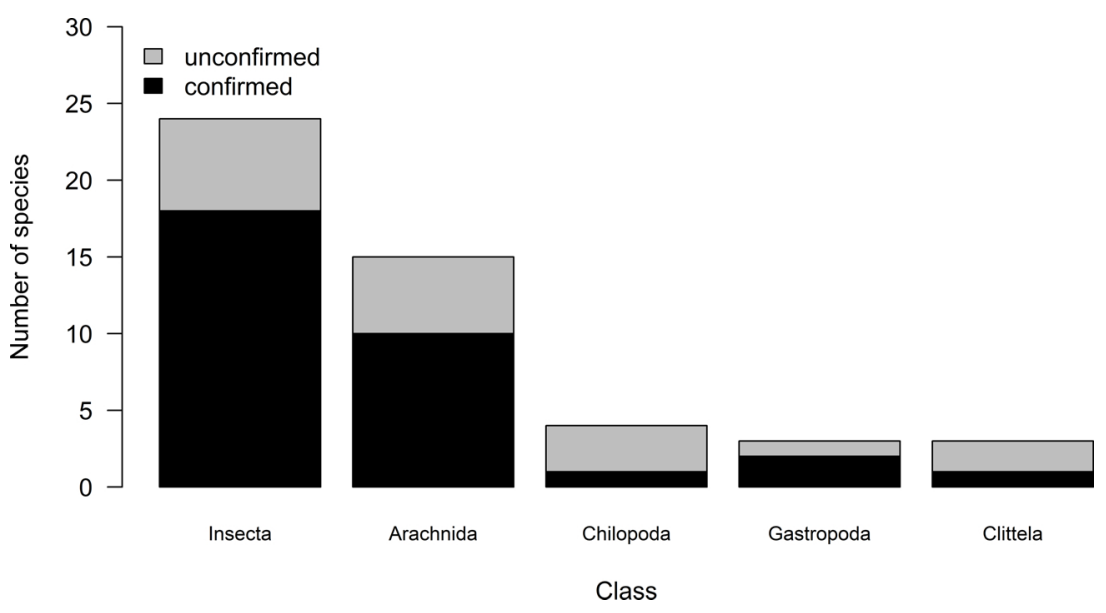

Fig. 1. The number of terrestrial invertebrate species (excluding spiders) per class obtained from the South African pet trade. Confirmed are species with names used in the pet trade that are confirmed by GBIF and/or ITIS (accessed 12 February 2017) while unconfirmed represents species with names used in the pet trade that were not confirmed by GBIF and or ITIS (accessed 12 February 2017). food, while one of these species is also kept as a pet (Fig. 3). All the recorded Arachnida were scorpions (tarantulas were excluded from this analysis) and most pet species were scorpions. Only one species, the Madagascar hissing cockroach (Gromphadorhina portentosa) is used as both a pet and as pet food.

We did not find any species reported to be invasive elsewhere in the world. A total of 48 published literature sources were used to provide data on impact, with an average of three publications per species (for species where there were records of impact). Three quarters of the species scored using EICAT had no records of impact and so were classified as Data Deficient. Nine species had records of environmental impact, but these were all of Minimal Concern (Fig. 4a). Socio-economic impacts were observed more frequently and were slightly greater in magnitude, though again most species (22 out of 36) were Data Deficient, and half of the remaining species were classified as Minimal Concern or Minor (Fig. 4b). Two species were recorded as having Moderate socio-economic impacts (Fig. 4b): the scorpions Hottentotta saulcyi and Mesobuthus eupeus are reported to sting people causing severe pain and sometimes death (Table A.1). The recorded environmental impacts were through three mechanisms (transmission of diseases to native species, parasitism and competition), and the socioeconomic impacts through two constituents of human well-being (safety, material and immaterial assets).

\section{Discussion}

Terrestrial invertebrates have been introduced for many purposes (Kumschick et al., 2016) including for: animal feed (Kenis et al., 2014), pets (Edward \& Hibbard, 1999), food for pets (Haggett, 2013), habitat and soil improvement (Baker, Brown, Butt, Curry, \& Scullion, 2006), live exhibits (Boppre \& Vane-Wright, 2012), conservation purposes (Winston et al., 2014), the silk production (Murakoshi, Chang, \& Tamura, 1972), and ornamental trade (New, 2008). We found that the pet trade in South Africa (aside from the tarantula trade) can be characterised as a few species widely sold as food for pets, a lower number of species sold as pets themselves, and a few sold as cleaners of pet cages. The trade is a mix of physical pet shops, trade over the internet, and through expositions. There are on-going problems with species identification, and this creates problems for compiling species inventories for the pet trade as species are sold only under trade names. An accepted species name was provided by the traders for only 36 of the 53 taxa. Our DNA barcoding however showed promising results as nine out of 11 species were correctly identified while two species matched with species of the same genus but different species names. The most available species in the pet trade are used as food for pets with the preferred species being house crickets (Acheta domesticus), mealworms (Tenebrio molitor) and superworms (Zophobas morio). There is a lack of a)

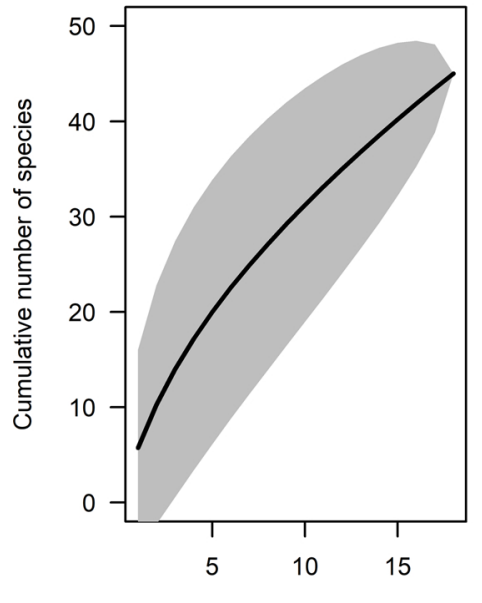

Number of websites b)

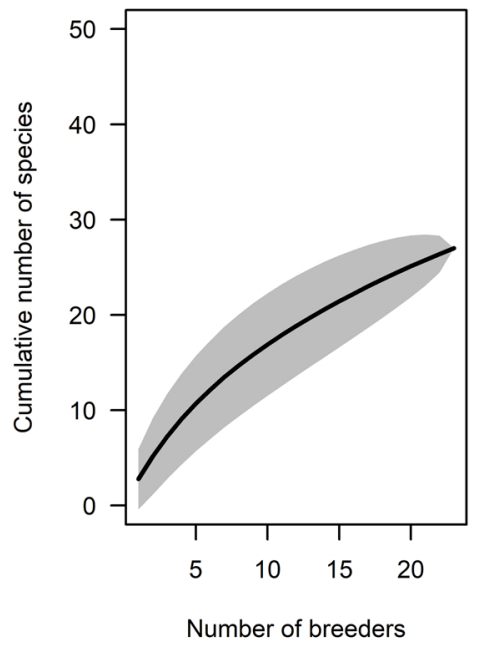

c)

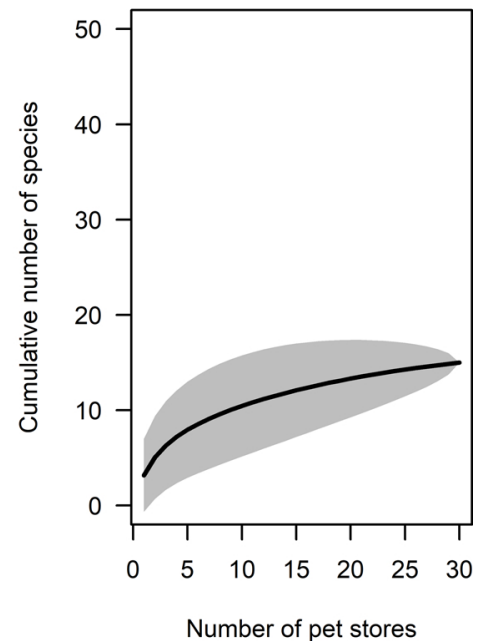

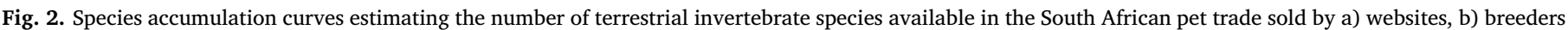

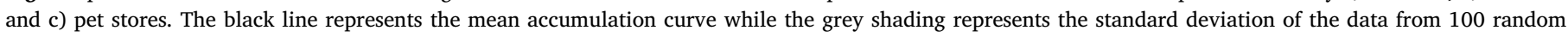
permutations using the 'vegan' package in R (Oksanen et al., 2017). 


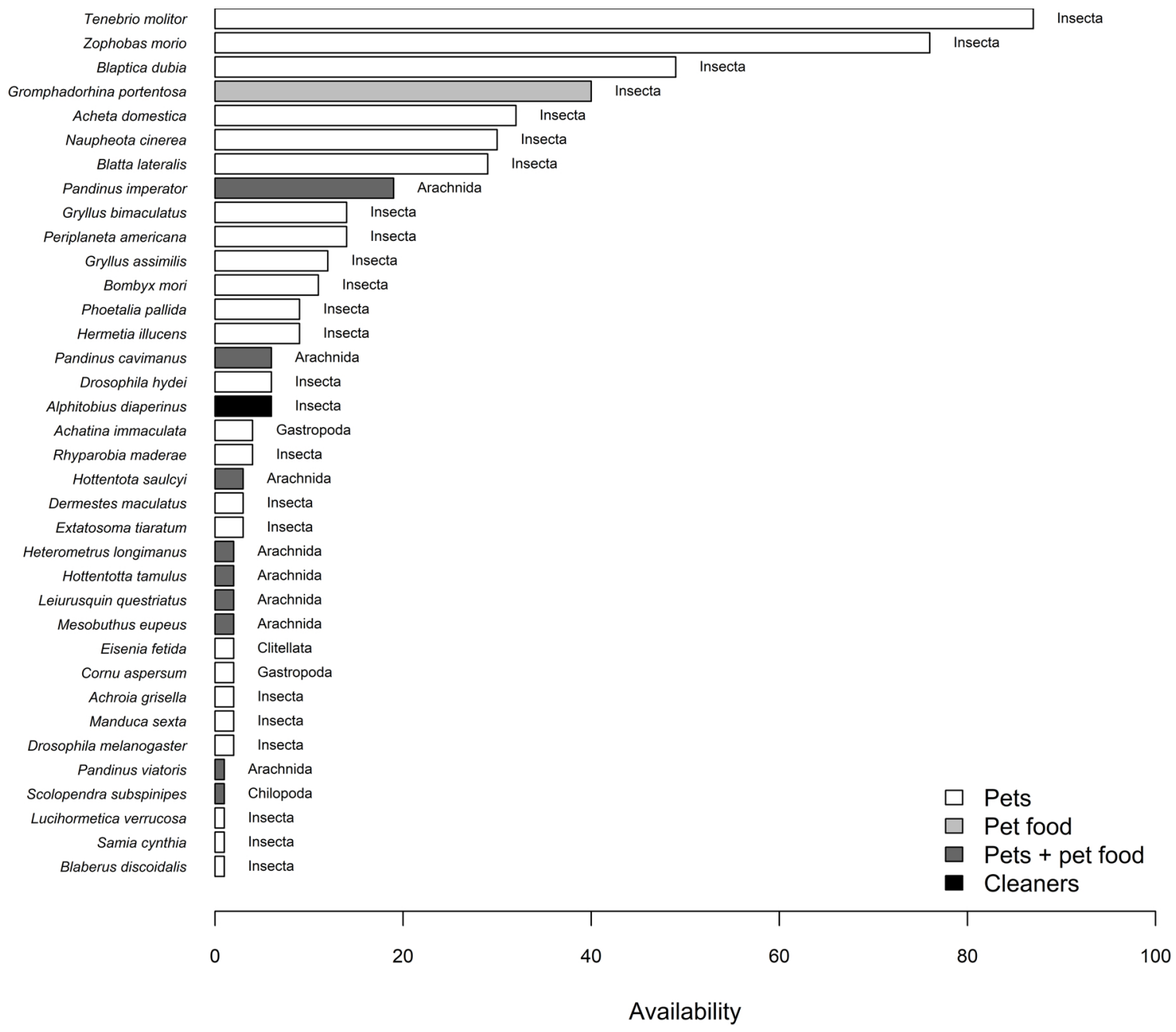

Fig. 3. Availability index of terrestrial invertebrate species (excluding spiders) sold in the South African pet trade. The index is the number of pet stores, websites or expositions at which a particular species was available. The colour of the bars indicates the use of the species.

evidence that the current trade poses significant invasions risks. Below we discuss the size of the trade, identity of the species traded, and the risks posed by these alien terrestrial invertebrates then conclude with a discussion on the consequences for regulation.

\subsection{Size of the trade}

Although we did not have data on volumes of trade, it appears that more species are sold online than at pet stores and expositions. The number of distinct named taxa recorded in this study $(n=53)$ is a)

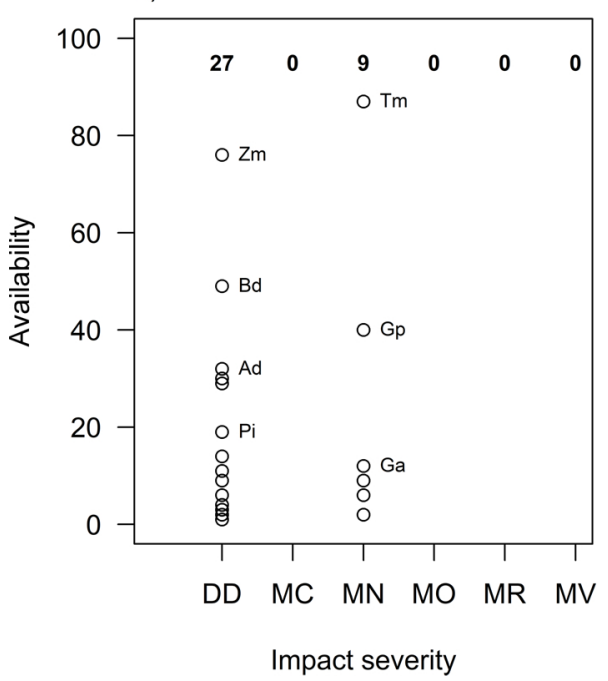

b)

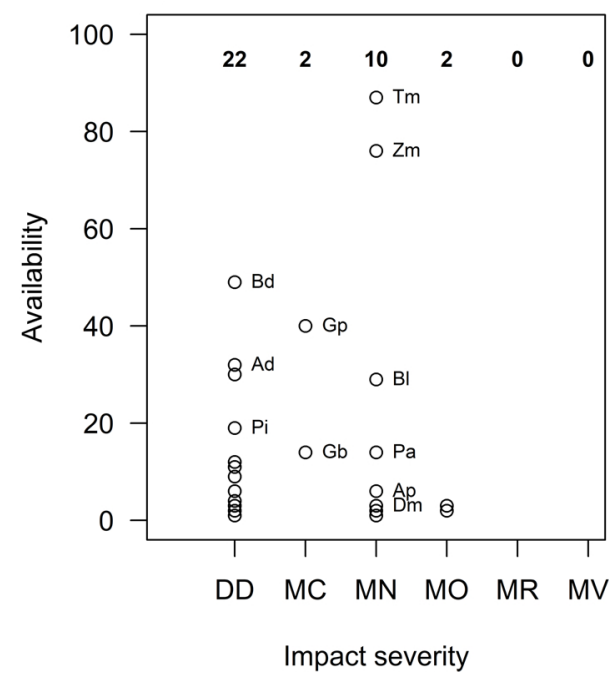

Fig. 4. The relationship between the availability of 36 alien terrestrial invertebrate species in the South African pet trade and the negative impacts of the species as recorded elsewhere in the world based on: a) Environmental Impact Classification for Alien Taxa (Hawkins et al., 2015), and b) SocioEconomic Impact Classification for Alien Taxa (Bacher et al., 2018) scores. The species indicated on the figure are: $\mathrm{Ad}=$ Acheta domesticus, $\mathrm{Ap}=$ Alphitobius diaperinus, $\mathrm{Bd}=$ Blaptica dubia, $\mathrm{Bl}=$ Blatta lateralis, $\mathrm{Dm}=$ Dermestes maculatus, $\mathrm{Gp}=$ Gromphadorhina portentosa, $\mathrm{Ga}=$ Gryllus assimilis, $\mathrm{Gb}=$ Gryllus bimaculatus, $\mathrm{Pa}=$ Periplaneta americana, $\mathrm{Pi}=$ Pandinus imperator, $\mathrm{Tm}=$ Tenebrio molitor, $\mathrm{Zm}=$ Zophobas morio. The numbers at the top of the figures are the number of species with recorded impact per category. DD = Data Deficient, MC $=$ Minimal Concern, MN = Minor, $\mathrm{MO}=$ Moderate, $\mathrm{MR}=$ Major and MV $=$ Massive. 
smaller than other groups studied in the South African pet trade e.g. $\sim 200$ species of tarantulas (Shivambu, 2018), 266 species of alien reptile (van Wilgen, Wilson., Elith, Wintle, \& Richardson, 2010), although only three alien amphibian species have been reported (Measey et al., 2017). Our estimate of the number of species traded is likely to be a large underestimate (Fig. 2), and websites had a greater diversity of taxa on offer (and were probably more under-sampled) than pet stores and breeders. Facebook was used as one of the leading social media sites. This suggests that there are probably many more species being kept or traded that were not recorded in our survey. Notably the species accumulation curve for websites suggests that there might be a large diversity of alien terrestrial invertebrates sold online that we did not record. There seems to be a greater number of species sold on websites in comparison to expositions and pet stores. This suggests that, as for other such organisms (Martin \& Coetzee, 2011), e-commerce is a major source of terrestrial invertebrate species that are traded. The trade was likely under-sampled as sampling occurred over a limited period of time and pet store sampling was only focused on four big cities. Additionally, pet stores and expositions only list the taxa that they currently have available for purchase as opposed to everything that is traded (some species could be temporarily out of stock) and as a consequence there were new species at each exposition. The short period of time over which the study was conducted also means that we cannot assess how the trade has developed over time. However, the more alien terrestrial invertebrate species are introduced to South Africa, the higher the chance that some of these species escape or are released and establish self-sustaining populations (Lockwood et al., 2009).

\subsection{Identity of the traded species}

In order to monitor species in the pet trade effectively, the identity of the species needs to be known (Sanders et al., 2008; Schlaepfer, Hoover, \& Dodd, 2005). This plays an important role in risk assessment as scientific names are a link to the literature on species traits and behaviour (Schlaepfer et al., 2005; van Riemsdijk, Van Niuwenhuize, MartineZ-Solano, Arntzen, \& Wielstra, 2017). The use of common names in the pet trade presents a challenge for compiling species inventories as it is often difficult to link the common name to the correct scientific name. In this study, a total of 17 unconfirmed species (species names that could not be verified on GBIF and ITIS) were found. We found several terrestrial invertebrate species sold only under trade names and multiple common names were in use for a single species. This can create problems when compiling a list of species that are available through the pet trade (Patoka, Kalous, \& Kopecky, 2014). In the Czech Republic, crayfish were reported to be sold under names of other species, out-dated names and only by a trade name (Patoka et al., 2014). The use of different names and spelling errors could lead to the misidentification of species (Keller \& Lodge, 2007).

Pet store owners and breeders can misidentify species due to morphological similarities and lack of appropriate expertise for species identification (Natusch \& Lyons, 2012). Many tarantula species have been misidentified due to morphological similarities (Mendoza \& Francke, 2017; Shivambu, 2018). Additional problems occur if species are incorrectly identified, and if hybridisation occurs as a result of species mixing (Natusch \& Lyons, 2012). Furthermore, species can be mislabelled intentionally to hide the trade of species listed under Convention on International Trade of Endangered Species (CITES, 2013). Mislabelling on imports of marine fish is used to hide the trade in CITES listed species, for example in the United States of America, South African hake (Merluccius capensis) has been changed or renamed to scarlet snapper (Bornatowski, Braga, \& Vitule, 2013), while shop owners have intentionally renamed tilapia (Oreochromis spp.) as red snapper (Lutjanus campechanus) to deceive customers (Tennyson, Winters, \& Powell, 1997). Overall, misidentification does not seem to be highly prevalent in this study.

Reference sequences were available for all species tested and the taxonomy of the terrestrial invertebrate species selected for DNA barcoding is well resolved (Barcode of Life Database, 2018). Of the 11 species analysed in this study using DNA barcoding only two were incorrectly identified. All specimens sold as Pandinus imperator (the most popular pet species in this study) were found to be closer to Pandinus viatoris on BOLD, possibly a misidentification in the trade [although $P$. imperator is reported to be a popular species in the pet trade globally (Dombrowski et al., 2007)]. Second, all specimens sold as Achatina immaculata were identified as Achatina fulica, albeit with a low percentage match. This might indicate that these species could be a hybrid of A. fulica (Natusch \& Lyon, 2012) (Fig. S1). Of the unconfirmed species, two snails were sold under the common names "Giant African land snail" and "African land snail" without any knowledge of the scientific names or where they come from. These common names are similar to those that are used for A. fulica, a highly invasive species (Lowe, Browne, Boudjelas, \& De Poorter, 2000). In recent pet store surveys (Shivambu, 2019, pers. comm.), snails that appear to be $A$. fulica were recorded. It is possible that this species, which is prohibited under South African legislation [the NEM:BA A\&IS Regulations (DEA, 2014)], is present in the pet trade despite not being recorded in this study. Further investigation of these snails is required.

\subsection{The risks posed}

Our study revealed that most terrestrial invertebrates in the South African pet trade are being used as food for pets such as reptiles and other invertebrates like tarantulas. The trade in reptiles and tarantulas has been reported to be increasing in South Africa (van Wilgen et al., 2010; Shivambu, 2018). It is possible that this leads to an increasing demand for terrestrial invertebrates as food for these species, e.g. mealworms (Tenebrio molitor) and house crickets (Acheta domesticus) (van Wilgen et al., 2010 ; Shivambu, 2018). Most pet store owners and breeders recommended Tenebrio molitor, Acheta domesticus, superworms (Zophobas morio) and dubia roach (Blaptica dubia) as pet food for reptiles and tarantulas (T. Nelufule, pers. obs.). These species are preferred as they are highly nutritious and easy targets as they are slow moving and do not fly (Rumpold \& Schluter, 2013).

We found considerable variation in the availability of species in our study. In a study on reptiles, van Wilgen et al. (2010) suggested that colour pattern, and species that are larger and easier to breed influence species availability in the pet trade in South Africa. Many reptiles are sold as pets whereas many of the species recorded in this study are sold as pet food and, therefore, the drivers of variation in species availability are likely to differ. For pet food, potential drivers include how easy they are to breed, how nutritious the species is, or whether they can fly or are easy to catch, while important factors for species that are used to clean cages include feeding behaviour (i.e. species that can feed on the pet food remains). Variables that could have influenced the availability of pet species in this study include the rarity of the species, size, longevity, productivity and higher profit (species that could make more money for the breeder) (Chucholl, 2013; Courchamp et al., 2006; Su, Cassey, \& Blackburn, 2015; CEC, 2017; Vall-1losera \& Cassey, 2017).

As far as we could ascertain, none of the terrestrial invertebrates recorded in the trade in South Africa have been reported as invasive anywhere in the world. In all but three cases, their impacts were of either Minimal Concern, Minor or Moderate (cf. Bacher et al., 2018 and Hawkins et al., 2015), the main exception being that venomous scorpions that pose a threat to human health. The lack of recorded impacts (and of invasions) could be due to a lack of recording. Alien insects and other terrestrial invertebrates are generally not well studied in comparison to alien species in other taxonomic groups (except when introduced for biocontrol) (Roques et al., 2009), and they are inconspicuous, which might mean they are not easily detected once introduced. Species assessed using SEICAT that have Moderate impacts have a low availability index, whereas species with high availability have Minor impacts. Two scorpions, Hottentota saulcy and Mesobuthus 
eupeus can have Moderate impacts on human health as they can sting people and cause severe pain, erythema, renal failure, blurred vision and death (Kularatne et al., 2015; Sagheb, Sharifian, Moini, \& Sharifian, 2012; Sofer \& Gueron, 1988; Sofer, Shalev, Weizman, Shahak, \& Gueron, 1991). According to SEICAT, these species cause Moderate impacts on human health as their impacts have resulted in permanent changes to society (socio-economic communities) due to (extremely rare) loss of life.

The different purposes of the species traded could also influence the risk of invasion. For example, species that are sold as pets could be sold in low numbers but they are often long lived and are more likely to be released as people often prefer to release their unwanted pets rather than kill them (Hulme et al., 2008; Stringham \& Lockwood, 2018). Although there is limited understanding of the factors that influence the likelihood that a species will be released, a recent study on this aspect of the pet trade has been undertaken by Maceda-Veiga et al., 2019. Their study assessed the effectiveness of the legislation for managing invasive species seven years after the legislation was implemented in Spain (the ban of prioritised invasive species sales) with the aim to reduce the release of invasive species. They found that invasive species such as Trachemys spp. are prevalent in urban lakes, which suggests that species are still being released (Maceda-Veiga et al., 2019). In contrast, species that are sold as pet food are likely to be sold in high numbers, less likely to be deliberately released (unless the pet they were to feed had died), and be much more likely to escape (as there is less of an incentive to contain them.

\subsection{Recommendations and conclusions}

None of the taxa identified pose a clear and immediate threat to South Africa (aside from the threat posed by venomous scorpions). Only one taxon in the group has been recorded as established in South Africa (the Indian stick insect, Carausius morosus) (Brock, 1998). Parallel to this study we completed a risk analysis of $C$. morosus using a risk analysis framework for South Africa (Kumschick, Wilson, \& Foxcroft, 2018; see Appendix B). This found that the threat posed by C. morosus species warrants its regulation. Given the evidence from this study it seems unlikely, however, that any of the species recorded here pose an unacceptable risk. It would, of course, be prudent to conduct a detailed risk analysis on each species [e.g. as per Kumschick et al. (2018)] including an analysis of their potential distribution in South Africa (providing there are sufficient distribution records, see Nelufule, 2018). But at present, there is no special reason that any of the taxa should be prioritised for a risk analysis.

Our study does not, however, prove the trade in alien invertebrates poses an acceptable risk to South Africa. Around a third of species recorded could not be assigned a valid species name; for most taxa there is simply no data on impacts; our data suggest there are many taxa in the trade that have not been recorded here; and the trade is arguably too recent for the full consequences in terms of invasions to have been realised. For example, it was not clear which species of earthworm was sold for soil improvement or for how long, but invasive earthworms are known to have caused impacts elsewhere in the world where they have had a long history of sale and spread by humans (Keller et al., 2007). There might, therefore, be a significant invasion debt (Rouget et al., 2016). Many species could still come from abroad through the international trade, but the international trade (species that are being offered for sale in other countries outside South Africa) was excluded from this study. Therefore we recommend that the pet trade is monitored; a species inventory is developed and maintained; species that pose a high risk are banned from trade; and a relationship is built with the industry so that species that pose little risk can be used freely, and any instances of invasion (or concern about potential invasions) can be detected rapidly and acted upon.

\section{Declaration of conflicting interest}

There is no conflict of interest from all authors

\section{Acknowledgements}

The South African Department of Forestry, Fisheries, and the Environment (DFFEE) are thanked for funding noting that this publication does not necessarily represent the views or opinions of DFFtE or its employees. We also acknowledge the DSI-NRF Centre of Excellence for Invasion Biology for their support. We thank two anonymous referees for comments which helped to improve the manuscript.

\section{Appendix A. Supplementary data}

Supplementary material related to this article can be found, in the online version, at doi:https://doi.org/10.1016/j.jnc.2020.125831.

\section{References}

Bacher, S., Blackburn, T. M., Essl, F., Genovesi, P., Heikkila, J. M., Jones, G., et al. (2018). Socio-economic impact classification of alien taxa (SEICAT). Methods in Ecology and Evolution, 9, 159-168.

Baker, G. H., Brown, G., Butt, K., Curry, J. P., \& Scullion, J. (2006). Introduced earthworms in agricultural and reclaimed land: Their ecology and influences on soil properties, plant production and other soil biota. Biological Invasions, 8, 1301-1316.

Barcode of Life Database. (2018). http://www.barcodinglife.org/accessed 14 March 2018

Bartlett, P., Griswold, B. D. V. M., \& Bartlett, R. D. (2001). Reptile, amphibians and invertebrates: An identification and care guide. United States of America: Barrons.

Blackburn, T. M., Essl, F., Evans, T., Hulme, P. E., Jeschke, J. M., Kühn, I., et al. (2014). A unified classification of alien species based on the magnitude of their environmental impacts. PLoS Biology, 12(5), e1001850.

Boppre, M., \& Vane-Wright, R. I. (2012). The butterfly house industry: Conservation risks and education opportunities. Conservation and Society, 10, 285-303.

Bornatowski, H., Braga, R. R., \& Vitule, J. R. S. (2013). Shark mislabelling threatens biodiversity. Science magazine, 340(6135), 923.

Broad, S., Mulliken, T., \& Roe, D. (2003). The nature and extent of legal and illegal trade in wildlife. In S. Oldfield (Ed.). The trade in wildlife, regulation for conservation (pp. 322). London: Earthscan Publications Ltd.

Brock, P. D. (1998). New records of alien stick insects. Phasmid Stud, 7, 39-40.

Bush, E. R., Baker, S. E., \& Macdonald, D. W. (2014). Global trade in exotic pets 20062012. Conservation Biology, 28, 663-676.

Cadi, A., \& Joly, P. (2003). Competition for basking places between the endangered European pond turtle (Emys orbicularis galloitalica) and the introduced red-eared turtle (Trachemys scripta elegans). Canadian Journal of Zoology, 81, 1392-1398.

Cadi, A., \& Joly, P. (2004). Impact of the introduction of the red-eared slider (Trachemys scripta elegans) on survival rates of the European pond turtle (Emys orbicularis). Biodiversity and Conservation, 13, 2511-2518.

Cambray, J. A. (2003). Impact on indigenous species biodiversity caused by the globalisation of alien recreational freshwater fisheries. Hydrobiologia, 500, 217-230.

Chucholl, C. (2013). Invaders for sale: Trade and determinants of the introduction of ornamental freshwater crayfish. Biological Invasions, 15, 125-141.

Convention on Biological Diversity (2013). Aichi biodiversity targets. [Online] 611 Available at: http://www.cbd.int/sp/targets/ accessed 14 March 2018.

Convention on International Trade in Endangered Species. (2013). Appendix II (www. cites.org/eng/news/pr/2013/20130314_cop16.php)/Accessed 18 July 2018.

Courchamp, F., Angulo, E., Rivalan, P., Hall, R. J., Signoret, L., Bull, L., et al. (2006). Rarity value and species extinction: The anthropogenic Allee effect. PLoS Biology, 4, 2405-2410.

Department of Environmental Affairs (2014). In DEA (Ed.). National environmental management: Biodiversity act 2004 (act No. 10 of 2004) alien and invasive species regulations, 2014 (pp. 3-32). Pretoria: Government Gazette.

Department of Environmental Affairs (2016). National environmental management: Biodiversity act 2004 (act No. 10 of 2004) alien and invasive species lists, 2016, vol 864. Pretoria: Government Gazette of South Africa.

Derraik, J. G. B., \& Phillips, S. (2010). Online trade poses a threat to biosecurity in New Zealand. Biological Invasions, 12, 1477-1480.

Dombrowski, M. S., DVM, RDV, MSpVM, DACZM, \& DABVP-Avian (2007). Emergency care of invertebrates. The Veterinary Clinics of North America Exotic Animal Practice, 10, 621-645.

Edward, G. B., \& Hibbard, K. L. (1999). Mexican redrump tarantula, Brachypelma vagans (Ausserer) (Arachnida : Araneae: Theraphosidae). DPI Entomology Circular, 287, 13.

Ernst, C. H., \& Lovich, J. E. (2009). Turtles of the United States and Canada (2nd ed.). United States of America: The John Hopkins.

Faulkes, Z. (2010). The spread of the parthenogenetic marbled crayfish, Marmorkrebs (Procambarus sp.), in the North American pet trade. Aquatic Invasions, 5, 447-450.

Global Biodiversity Information Facility. (2017). https://www.gbif.org/Accessed 12 Febraury 2017.

Haenen, O. L. M., Way, k., Bergmann, S. M., \& Ariel, E. (2004). The emergence of koi herpesvirus and its significance to European aquaculture. Bulletin of the European 
Association of Fish Pathologists, 24, 293.

Haggett, D. (2013). Breeding insects as feeder food. East Sussex: Mantis Press.

Hawkins, C. L., Bacher, S., Essl, F., Hulme, P. E., Jeschke, J. M., Kühn, I., et al. (2015). Framework and guidelines for implementing the proposed IUCN Environmental Impact Classification for Alien Taxa (EICAT). Diversity \& Distributions, 21, 1360-1363.

Hulme, P. E. (2012). Weed risk assessment: a way forward or a waste of time? The Journal of Applied Ecology, 49, 10-19.

Hulme, P. E., Bacher, S., Kenis, M., Klotz, S., K"uhn, I., Minchin, D., et al. (2008). Grasping at the routes of biological invasions: A framework for integrating pathways into policy. The Journal of Applied Ecology, 45, 403-414.

Integrated Taxonomic Information System (2017). https://www.itis.gov/Accessed 12 February 2017.

International Union for Conservation of Nature (2020). IUCN EICAT categories and criteria. The environmental impact classification for alien taxa (EICAT): First edition. Gland, Switzerland and Cambridge, UK: IUCN.

Karesh, W. B., Cook, R. A., Bennett, E. L., \& Newcomb, J. (2005). Wildlife trade and global disease emergence. Emerging Infectious Diseases, 11, 1000-1002.

Keller, R. P., \& Lodge, D. M. (2007). Species invasions from commerce in live aquatic organisms: Problems and possible solutions. BioScience, 57, 428-436.

Keller, R. P., Cox, A. N., Van Loon, C., Lodge, D. M., Herborg, L., \& Rothlisberger, J. (2007). From bait shops to the forest floor: Earthworm use and disposal by anglers. The American Midland Naturalist, 158, 321-328.

Kenis, M., Kone, N., Chrysostome, C. A. A. M., Devic, E., Koko, G. K. D., Clottey, V. A., et al. (2014). Insects used for animal feed in West Africa. Entomological, 2, 107-114.

Kikillus, K. H., Hare, K. M., \& Hartley, S. (2012). Online trading tools as a method of estimating propagule pressure via the pet-release pathway. Biological Invasions, 14, 2657-2664.

Kopecky, O., Patoka, J., \& Kalous, L. (2016). Establishment risk and potential invasiveness of the selected exotic amphibians from pet trade in the European Union. Journal for Nature Conservation, 31, 22-28.

Kularatne, S. A. M., Dinamithra, N. P., Sivansuthan, S., Weerakoon, K. G. A. D., Thillaimpalam, B., Kalyanasundram, V., et al. (2015). Clinico-epidemiology of stings and envenoming of Hottentotta tamulus (Scorpiones: Buthidae), the Indian red scorpion from Jaffna Peninsula in northern Sri Lanka. Toxicon, 93, 85-89.

Kulhanek, S. A., Ricciardi, A., \& Leung, B. (2011). Is invasion history a useful tool for predicting the impacts of the world's worst aquatic invasive species? Ecological Applications, 21, 189-202.

Kumschick, S., Devenish, A., Kenis, M., Rabitsch, W., Richardson, D., \& Wilson, J. R. U. (2016). Intentionally introduced terrestrial invertebrates: Patterns, risks, and options for management. Biological Invasions, 18, 1077-1088.

Kumschick, S., Wilson, J. R., \& Foxcroft, L. C. (2018). Framework and guidelines for conducting risk analyses for alien species. Preprints.. https://doi.org/10.20944/ preprints201811.0551.v1.

Latombe, G., Pyšek, P., Jeschke, J. M., Blackburn, T. M., Bacher, S., Capinha, C., et al. (2016). A vision for global monitoring of biological invasions. Biological Conservation, 213, 295-308.

Lockwood, J. L., Cassey, P., \& Blackburn, T. M. (2009). The more you introduce the more you get: The role of colonization pressure and propagule pressure in invasion ecology. Diversity \& Distributions, 15, 904-910.

Lockwood, J. L., Welbourne, D. J., Romagosa, C. M., Cassey, P., Mandrak, N. E., Strecker, A., et al. (2019). When pets become pests: The role of the exotic pet trade in producing invasive vertebrate animals. Frontiers in Ecology and the Environment. https:// doi.org/10.1002/fee.2059.

Lowe, S., Browne, M., Boudjelas, S., \& De Poorter, M. (2000). 100 of the World's worst invasive alien species. A selection from the global invasive species database. Aliens 12 Available at: http://www.issg.org/database/species/reference_fi les/100English.pdf/ Accessed March 2018.

Maceda-Veiga, A., Escribano-Alacid, J., Martı́nez-Silvestre, A., Verdaguer, I., \& Nally, R. M. (2019). What's next? The release of exotic pets continues virtually unabated 7 years after enforcement of new legislation for managing invasive species. Biological Invasions, 21, 2933-2947.

Magona, N., Richardson, D. M., Le Roux, J. J., Kritzinger-Klopper, S., \& Wilson, J. R. U. (2018). Even well-studied groups of alien species might be poorly inventoried: Australian acacia species in South Africa as a case study. Neobiota, 39, 1-29.

Marr, S. M., Ellender, B. R., Woodford, D. J., Alexander, M. E., Wasserman, R. J., Ivey, P., et al. (2017). Evaluating invasion risk for freshwater fishes in South Africa. Bothalia: African Biodiversity and Conservation, 47, 1-10.

Martin, G. D., \& Coetzee, J. A. (2011). Pet stores, aquarists and the internet trade as modes of introduction and spread of invasive macrophytes in South Africa. Water SA, 37, 371-380.

McGeoch, M. A., Spear, D., Kleynhans, E. J., \& Marais, E. (2012). Uncertainty in invasive alien species listing. Ecological Applications, 22, 959-971.

Measey, G. J., Davies, S., Vimercati, G., Rebelo, A., Schmidt, W., \& Turner, A. (2017). Invasive amphibians in southern Africa: A review of invasion pathways. Bothalia African Biodiversity and Conservation, 47, 1-12.

Mendoza, J., \& Francke, O. (2017). Systematic revision of Brachypelma red-kneed tarantulas (Araneae : Theraphosidae), and the use of DNA barcodes to assist in the identification and conservation of CITES-listed species. Invertebrate Systematics, 31 $157-179$.

Mori, E., Grandi, G., Menchetti, M., Tella, J. L., Jackson, H. A., Reino, L., et al. (2017). Worldwide distribution of non - Native Amazon parrots and temporal trends of their global trade. Animal Biodiversity and Conservation, 40, 49-62.

Murakoshi, S., Chang, C. F., \& Tamura, S. (1972). Increase in silk production by the silkworm, Bombyx mori L., due to oral administration of juvenile hormone analog. Biological Chemistry, 36, 695-696.

Natusch, D. J. D., \& Lyons, J. A. (2012). Exploited for pets: The harvest and trade of amphibians and reptiles from Indonesian New Guinea. Biodiversity and Conservation, $21,2899-2911$.

Nelufule, T. (2018). An assessment of alien terrestrial invertebrate species in the pet trade in South Africa. Masters thesis. University of Pretoria.

New, T. R. (2008). Are butterfly releases at weddings a conservation concern or opportunity? Journal of Insect Conservation, 12, 93-95.

Ng, T. H., Tan, S. K., Wong, W. H., Meier, R., Chan, S.-Y., Tan, H. H., et al. (2016). Molluscs for Sale: Assessment of freshwater gastropods and bivalves in the ornamental pet trade. PLOSONE, 11(8), e0161130.

Oksanen, J., Blanchet, F. G., Friendly, M., Kindt, R., Legendre, P., McGlinn, D., et al. (2017). Vegan: Community ecology package. R package version $2.4-4$. https://CRAN.Rproject.org $/$ package $=$ vegan .

Olson, L. J. (2006). The economics of terrestrial invasive species: A review of the literature. Agricultural Resources and Economics Review, 35, 178-194.

Papavlasopoulou, I., Vardakas, 1., Perdikaris, C., Kommatas, D., \& Paschos, I. (2013). Ornamental fish in pet stores in Greece: a threat to biodiversity? Mediterranean Marine Science, 15, 126-134.

Patoka, J., Kalous, L., \& Kopecky, O. (2014). Risk assessment of the crayfish pet trade based on data from the Czech Republic. Biological Invasions, 16, 2489-2494.

Peacock, D. S., van Rensburg, B. J., \& Robertson, M. P. (2007). The distribution and spread of the invasive alien common myna, Acridothere stristis L. (Aves: Sturnidae), in Southern Africa. South African Journal of Science, 103, 465-473.

Petersen, S. D., Mason, T., Akber, S., West, R., White, B., \& Wilson, P. (2007). Species identification of tarantulas using exuviae for international wildlife law enforcement. Conservation Genetics, 8, 497-502.

Picker, M., \& Griffiths, C. (2011). Alien and invasive animals, a south african perspective. Cape Town: Struik.

Picker, M., Griffiths, C., \& Weaving, A. (2002). Field guide of insects of South Africa. South Africa: Struik.

Polo-Cavia, N., Lopez, P., \& Martın, J. (2008). Interspecific differences in responses to predation risk may confer competitive advantages to invasive freshwater turtle species. Ethology, 114, 115-123.

Porter, S. D., \& Savignano, D. A. (1990). Invasion of polygyne fire ants decimates native ants and disrupts arthropod community. Ecology, 71, 2095-2106.

Regan, H. M., Colyvan, M., \& Burgman, M. A. (2002). A taxonomy and treatment of uncertainty for ecology and conservation biology. Ecological Applications, 12, 18-628.

Roques, A., Rabitsch, W., Rasplus, J.-Y., Lopez-Vamonde, C., Nentwig, W., \& Kenis, M. (2009). In DAISIE (Ed.). alien terrestrial invertebrates of Europe. Handbook of alien species in Europe (pp. 63-79). Berlin: Springer.

Rouget, M., Robertson, M. P., Wilson, J. R. U., Hui, C., Essl, F., Rentería, J. L., et al. (2016). Invasion debt—Quantifying future biological invasions. Diversity \& Distributions, 22, 445-456.

Roy, H. E., Peyton, J., Aldridge, D. C., Bantock, T., Blackburn, T. M., Britton, R., et al (2014). Horizon scanning for invasive alien species with the potential to threaten biodiversity in Great Britain. Global Change Biology, 20, 3859-3871.

Rumpold, B. A., \& Schluter, O. K. (2013). Nutritional composition and safety aspects of edible insects. Molecular Nutrition \& Food Research, 57, 802-823.

Sagheb, M. M., Sharifian, M., Moini, M., \& Sharifian, A. H. (2012). Scorpion bite prevalence and complications: Report from a referral centre in southern Iran. Tropical Doctor, 42, 90-91.

Sanders, J. G., Cribbs, J. E., Fienberg, H. G., Hulburd, G. C., Katz, L. S., \& Palumbi, S. R. (2008). The tip of the tail: Molecular identification of seahorses for sale in apothecary shops and curio stores in California. Conservation Genetics, 9, 65-71.

Schlaepfer, M. A., Hoover, C., \& Dodd, C. K. (2005). Challenges in evaluating the impact of the trade in amphibians and reptiles on wild populations. BioScience, 55, 256-264.

Shivambu, T. C. (2018). Risk assessment of tarantula in the pet trade in South Africa. Masters Thesis. University of Pretoria.

Sofer, S., \& Gueron, M. (1988). Respiratory failure in children following envenomation by the scorpion Leiurus quinuestriatus: Hemodynamic and neurological. Toxicon, 26, 931-939.

Sofer, S., Shalev, H., Weizman, Z., Shahak, E., \& Gueron, M. (1991). Acute pancreatitis in Children following envenomation by yellow scorpion Leiurus quinuestriatus. Toxicon, $29,125-128$.

Stringham, O. C., \& Lockwood, J. L. (2018). Pet problems: Biological and economic factors that influence the release of alien reptiles and amphibians by pet owners. The Journal of Applied Ecology, 55, 2632-2640 Su, S., Cassey, P., \& Blackburn T. M. (2015). The wildlife pet trade as a driver of introduction and establishment in alien birds in Taiwan. Biological Invasions, 18, 215-229.

Su, S., Cassey, P., \& Blackburn, T. M. (2015). The wildlife pet trade as a driver of introduction and establishment in alien birds in Taiwan. Biological Invasions, 18, 215-229.

Tennyson, J. M., Winters, K. S., \& Powell, K. (1997). A fish by any other name: A report on species substitution. Papers Presented at the 22nd Annual Meeting of Seafood Science the Technology Society of the Americas, 6-7.

Vall-llosera, M., \& Cassey, P. (2017). Do you come from a land down under? Characteristics of the international trade in Australian endemic parrots. Biological Conservation, 207, 38-46.

van Riemsdijk, I., Van Niuwenhuize, L., MartineZ-Solano, I., Arntzen, J. W., \& Wielstra, B. (2017). Molecular data reveal the hybrid nature of an introduced population of banded newts (Ommatotriton) in Spain. Conservation Genetics, 1-6.

van Wilgen, N. J., Wilson, J. R. U., Elith, J., Wintle, B. A., \& Richardson, D. M. (2010). Alien invaders and reptile traders: What drives the live animal trade in South Africa? Animal Conservation, 13, 24-32.

Vila, M., Espinar, J. L., Hejda, M., Hulme, P. E., Jarosık, V., Maron, J. L., et al. (2011). Ecological impacts of invasive alien plants: A meta-analysis of their effects on species, communities and ecosystems. Ecology Letters, 14, 702-708. 
Wan, F. H., Guo, J. Y., \& Wang, D. H. (2002). Alien invasive species in China: Their damages and management strategies. Biodiversity Science, 10, 119-125.

Weber, J., Panetta, F. D., Virtue, J., \& Phelong, P. (2009). An analysis of assessment outcome from eight years' operation of the Australian border weed risk assessment systems. Journal of Environmental Management, 90, 798-807.

Weir, R. P., Moody, N. J. G., Hyatt, A. D., Crameri, S., Voysey, R., Pallister, J., et al. (2012). Isolation and characterisation of a novel Bohle-like virus from two frog species in the Darwin rural area, Australia. Diseases of Aquatic Organisms, 99, 169-177.

Winston, R. L., Schwarzlander, M., Hinz, H. L., Day, M. D., Cock, M. J. W., \& Julien, M. H. (2014). Biological control of weeds: A world catalogue of agents and their target weeds, (5th Ed). FHTET-2014-04. USDA Forest Service, Morgantown: Forest Health

Technology Enterprise Team. 


\section{Appendix A}

The threats posed by the pet trade in alien terrestrial invertebrates in South Africa

\section{Journal for Nature Conservation}

Takalani Nelufule ${ }^{1,2 *}$, Mark P. Robertson ${ }^{1}$, John R.U. Wilson ${ }^{2,3}$, Katelyn T. Faulkner ${ }^{1,2}$, Catherine Sole ${ }^{4}$, Sabrina Kumschick ${ }^{2,3}$

Centre for Invasion Biology, Department of Zoology and Entomology, University of Pretoria, Pretoria, South
Africa $^{1}$

South African National Biodiversity Institute, Kirstenbosch Research Centre, Cape Town, South Africa ${ }^{2}$

Centre for Invasion Biology, Department of Botany and Zoology, Stellenbosch University, Stellenbosch, South Africa $^{3}$

University of Pretoria, Pretoria, South Africa ${ }^{4}$

*corresponding author: takalani.nelu@gmail.com

\section{Molecular methods}

DNA barcoding for confirmation of identity

To determine the correct identity of species in the pet trade we performed molecular analysis of a selected number of species. We selected species that were most available during the surveys (species with availability index of nine and above, see Online Resource 1) and those regulated under the South African National Environmental Management: Biodiversity Act, Alien and Invasive Species Regulations (NEMBA: A\&IS Regulations) (DEA, 2014). To get a range of samples, specimens of each species were purchased from three different pet stores where possible. The majority of the proposed species had reference sequences available on publicly accessible databases. For this purpose, 39 specimens belonging to 13 species were selected for DNA barcoding. For some species that were selected for DNA barcoding, the required three specimens could not be found for purchase these include: Extatosoma tiaratum, Hermetia illucens, Achatina immaculata and Gryllus assimilis. In addition, DNA did not amplify for three specimens of Blaptica dubia. As a result, the final dataset consisted of 27 specimens belonging to 11 species.

\section{DNA extraction, amplification and sequencing}

The individuals were euthanized and preserved in $99.9 \%$ ethanol. Total genomic DNA was extracted from a leg of each specimen using a Machery-Nagel NucleoSpin Tissue Kit (Duren, Germany), following the manufacturer's specifications. The mitochondrial COI gene was amplified by polymerase chain reaction (PCR) using the forward primer LC0-1490 (GGTCAACAAATCATAAAGATATTGG) and the reverse primer HCO2198 (TAAACTTCAGGGTGACCAAAAAATCA) (Folmer et al., 1994). The PCR reaction contained 20 pmol of each primer (forward and reverse), a single unit of TakaraTaq (Emerald Amp®MAX HS PCR Master mix, TAKARA BIO INC., Otsu, Shiga, Japan), 50 - $100 \mathrm{ng}$ of DNA template made up to 25ul with distilled water.

The PCR denaturation step occurred at $94{ }^{\circ} \mathrm{C}$ for 9 minutes; 35 cycles of $94{ }^{\circ} \mathrm{C}$ for 45 seconds; annealing at 50 ${ }^{\circ} \mathrm{C}$ for 45 seconds and extension at $72{ }^{\circ} \mathrm{C}$ for 60 seconds with a final elongation step at $72{ }^{\circ} \mathrm{C}$ for 10 minutes. Following PCR, the samples were checked using agarose gel electrophoresis stained with goldview. The PCR products were purified using Machery-Nagel NucleoSpin Gel and PCR clean-up kit following the manufacturer's specifications. Purified PCR products were sequenced in both directions using BigDye ${ }^{\circledR}$ Terminator v3.1 Cycle Sequencing Kit (Applied Biosystems, Foster City, USA) and analyzed on the ABI PRISM 3130XL sequencer. The DNA Sequences were aligned with CLC Workbench Version 7.9.1 (QIAGEN Aarhus A/S: www.qiagenbioinformatics.com) and trimmed using MEGA7 (Kumar et al., 2016).

Molecular analysis

A BLAST search (Altschul et al., 1997) for highly similar sequences was performed on the Barcode of Life System (BOLD, 2018) in order to confirm the accuracy of species identification. A high match was considered for species with a BLAST match of greater than $98 \%$, medium match for a match between $90-98 \%$ and low match for species with a BLAST match of below 90\% (Altschul et al., 1990). 
Two COI reference sequences were downloaded from the publicly accessible databases for each specimen. In cases where there were no available reference sequences, congeners were incorporated. Reference sequences were used in order to confirm the accuracy of names used for the specimens obtained in the South Africa pet trade. The downloaded sequences were also incorporated in phylogenetic analyses for comparison with the sequences generated from the terrestrial invertebrate specimens. Two $\mathrm{CO} 1$ gene sequences from closely related genera to the terrestrial invertebrate sequences, the red wood ant (Formica rufa) (KR928491) and emperor moth (Gonimbrasia belina) (SATW060), were downloaded and included as outgroups to root the phylogeny.

The best model of sequence evolution was determined using the Akaike Information Criterion (AIC) and Bayesian Information Criterion (BIC) by implementing jModelTest (Posada, 2008). Phylogenetic analyses were performed using different tree building methods implemented in MEGA7 (Kumar et al., 2016). Initially the Neighbor-joining method (Saitou \& Nei, 1987) based on uncorrected p-distance (Nei Kumar, 2000) was used and thereafter, Parsimony (Tamura et al., 2011) and Maximum likelihood (ML) (Guindon et al., 2010). A pairwise distance was used to calculate interspecific P-distance. Parsimony search used Subtree-PruningRegrafting (SPR) while the ML approach used the GTR $+\mathrm{I}+\mathrm{G}$ model estimated in jModel test with a discrete gamma distribution (Darriba et al., 2012). Nodal support for all resultant topologies was assessed using 500 bootstrap replicates (Felsenstein, 1981) and branches with less than $50 \%$ bootstrap support were collapsed.

All specimens are being stored at University of University of Pretoria in the Department of Zoology and Entomology and will be lodged in the Agricultural Research Council's National Insect Collection. All sequences were uploaded to the BOLD database.

\section{References}

Altschul, S. F., Gish, W., Miller, W., Myers, E. W., \& Limpman, D. J. (1990). Basic local alignment search tool. Journal of Molecular Biology, 215 403-410.

Altschul, S. F., Madden, T. L., Schaffer, A. A., Zhang, J., Zhang, Z., Miller, W., \& Lipman, D. J. (1997). Gapped BLAST and PSI-BLAST: A new generation of protein database search programs. Nucleic Acids Research, 25, 3389-3402.

Darriba D, Taboada GL, Doallo R and Posada D (2012) jModelTest 2: more models, new heuristics and parallel computing. Nature Methods, 9, 772.

Department of Environmental Affairs. (2014). National Environmental Management: Biodiversity Act 2004 (Act No. 10 of 2004) Alien and Invasive Species Regulations, 2014. (ed DEA), pp. 3-32. Government Gazette, Pretoria.

Felsenstein, J. (1981). Evolution Tree from DNA sequences: A maximum likelihood Approach. Journal of Molecular Evolution, 17, 368-376.

Folmer, O., Black, M., Hoeh, W., Lutz, R., \& Vrijenhoek, R. (1994). DNA primers for amplification of mitochondrial cytochrome c oxidase subunit I from diverse metazoan invertebrates. Molecular Marine Biology and Biotechnology, 3, 294-299.

Guindon, S., Dufayard, J-E., Lefort, V., Anisimova, M., Hordijk, W., \& Gascuel, O. (2010). New Algorithms and Methods to Estimate Maximum-Likelihood Phylogenies: Assessing the Performance of PhyML 3.0. Systematic Biology, 59, 307-321.

Kumar, S., Tamura, K., Jakobsen, I. B., \& Nei, M. (2001). MEGA2: molecular evolutionary genetics analysis software. Bioinformatics, 17, 244-1245.

Kumar, S., Stecher, G., \& Tamura, K. (2016). MEGA7: Molecular Evolutionary Genetics Analysis Version 7.0 for Bigger Datasets. Molecular Biology and Evolution, 33,1870-1874.

Nei, M., \& Kumar, S. (2000). Molecular evolution and phylogenetics. Oxford university press, Vancouver

Saitou, N., \& Nei, M. (1987). The Neighbor-joining Method: A New Method for Reconstructing Phylogenetic Trees. Molecular Biology and Evolution, 4, 406-425.

Tamura, K., Peterson, D., Peterson, N., Stecher, G., Nei, M., \& Kumar, S. (2011). MEGA5: Molecular Evolutionary Genetics Analysis Using Maximum Likelihood, Evolutionary Distance and Maximum Parsimony Methods. Molecular Biology and Evolution, 28, 2731-2739. 